Reprinted from Adultspan, Vol. 1, P. 13. (C) 1999 The American Counseling Association. Reprinted with permission. No further reproduction authorized with out written permission from the American Counseling Association: http://www.counseling.org

\title{
The Gay and Lesbian Affirmative Development (GLAD) Model: Facilitating Positive Gay Identity Development
}

\author{
John F. Marszalek III \\ Craig S. Cashwell
}

The Gay and Lesbian Affirmative Development (GLAD) model, a proactive, gay-affirmative counseling approach, is proposed. Parallels are drawn between Cass's (1979) Homosexual Identity Formation model and Ivey's (1990) cognitive-behavioral Developmental Counseling Therapy model to help counselors assess and facilitate gay and lesbian clients' cognitive development related to the formation of a positive sexual orientation identity.

Researchers have studied the way identity development, an important component of overall development (Chickering \& Reisser, 1993; Erikson, 1968), varies for diverse minority groups (Atkinson, Morten, \& Sue, 1993; Cass, 1990). In particular, research on the identity development of gay men and lesbians has been conducted to discover the processes through which they develop sexual orientation identities. A gay or lesbian identity includes having homosexual feelings, but "also implies that gay men [and lesbians] may feel somehow 'different' from their heterosexual counterparts apart from their choice of sexual partners" (Beard \& Glickauf-Hughes, 1994, p. 28). On the basis of their research, theorists have proposed identity models of the development of a gay or lesbian identity (Cass, 1990; Coleman, 1981/ 1982; Troiden, 1984, 1988).

Many authors have stressed the importance of counselors understanding gay and lesbian identity models and using a gay or lesbian affirmative counseling approach to help gay men or lesbians develop a positive sexual orientation identity (Fassinger, 1991; Hall \& Fradkin, 1992; Hancock, 1995; Malyon, 1993; McHenry \& Johnson, 1993), a developmental task that is

\footnotetext{
John F. Marszalek III is a counselor education in private practice in Boca Raton, Florida, and Craig S. Cashwell is a counselor educator in the Department of Counselor Education and Educational Psychology at Mississippi State University, Mississippi State. Correspondence regarding this article should be sent to John F. Marszalek III, PO Box 6012, Boca Raton, FL 33427 (e-mail: jmarszalek@psynet.net).
} 
directly related to psychological adjustment (Miranda \& Storms, 1989). A gay or lesbian affirmative counseling approach considers the influence of societal homophobia on an individual's development. Such an approach moves beyond the pathological view of homosexuality, views homosexuality as simply an alternative to heterosexuality, and seeks to affirm an individual's identity as gay or lesbian (Malyon, 1993). Included in gay and lesbian affirmative counseling is an understanding of the major issues that may arise during counseling with gay or lesbian clients, including identity issues, the impact of negative societal attitudes toward gay men or lesbians, discrimination in the legal, societal, and religious realms, samesex relationship dynamics, and the effect of AIDS on the gay or lesbian community (Fassinger, 1991; Hall \& Fradkin, 1992; Hancock, 1995; Malyon, 1993; McHenry \& Johnson, 1993; Shannon \& Woods, 1991).

Despite the fact that a developmental approach is a cornerstone of the counseling profession (Myers, 1992), developmental theory has relatively little influence on clinical practice for many counselors (Ivey, 1990). Similarly, although identity development is often included as a major issue in gay or lesbian affirmative counseling approaches, there is not a model for systematically incorporating identity development into an integrative developmental counseling model. Gay or lesbian affirmative counseling approaches usually involve applying specific techniques or specific theoretical schools such as self-psychology (Beard \& Glickauf-Hughes, 1994) or cognitive therapy (Kuehlwein, 1992) to identity development issues.

Ivey's (1990) Developmental Counseling Therapy (DCT) model provides justification for integrating various counseling techniques into an overall integrative developmental counseling approach. The DCT model is a cognitive-behavioral model that outlines a developmental counseling approach whereby counselors evaluate the cognitive level of clients and systematically select appropriate counseling interventions to facilitate client development. Ivey (1993) noted that there are parallels between Atkinson et al.'s (1993) Minority Identity Development Theory (MIDT), a model that outlines the identity development of African Americans and other societal minorities, and his DCT model. Furthermore, Ivey (1993) stated that by applying the DCT model to the MIDT model, counselors could help to facilitate minority identity development.

Correspondingly, counselors could facilitate sexual orientation identity development with gay and lesbian clients by applying the DCT model to Cass's (1990) Homosexual Identity Formation (HIF) model. The HIF model and other gay or lesbian identity models are similar to the MIDT model. Major tenets of both models are that societal minorities, such as gay men and lesbians or African Americans, experience both internal and external conflict regarding their identity. They experience internal conflict in the 
struggle between nonacceptance and acceptance of their identity, and they experience external conflict in their eventual positive perception of themselves as a minority versus the often negative societal view of their minority group (Ivey, 1993). The purpose of this article, then, is to promote a Gay and Lesbian Affirmative Development (GLAD) model that uses a parallelism between Cass's (1990) HIF model and Ivey's (1990) DCT model as a means for counselors to promote positive identity development with gay or lesbian clients.

\section{CASS'S HOMOSEXUAL IDENTITY FORMATION MODEL.}

The HIF model is the most cited in the literature on gay or lesbian identity development (Cass, 1979, 1984, 1990). Cass's model is viewed by many as the most comprehensive of gay or lesbian identity models because it integrates psychological and social components and, unlike most other models, is based on both qualitative and quantitative research (Brady $\&$ Busse, 1994; Chickering \& Reisser, 1993; Levine \& Evans, 1991). Cass (1979) based the HIF model on her observations of gay and lesbian clients, and she later developed the Homosexual Identity Questionnaire (Cass, 1984) to establish the model's validity. According to Cass (1984), "identity is perceived as a cognitive construct, the components of which are accompanied by unique affect. Identity is invariably translated into psychological activity (behavior) which in turn may result in changes occurring in identity" (p. 147). The formation of a gay or lesbian identity involves moving from what is defined by society and self as a heterosexual identity to a homosexual identity.

The process of a homosexual identity formation begins when people are able to acknowledge that there is something about their behavior that they define as "homosexual." This awareness can act as a trigger for a complex process of change that sees a person develop an increasingly unambiguous and accepted image of self as [gay or lesbian]. (Cass, 1990, p. 247)

Cass (1990) proposed a six-stage model to describe gay or lesbian identity development. Each stage is marked by a paradigm shift (possibly influenced by environmental factors), leading to changes in affect and behavior. The stages are as follows: (a) identity confusion in which individuals experience confusion as they begin to realize that their feelings and behaviors, previously defined by society and self as heterosexual, may be homosexual; (b) identity comparison in which individuals begin to accept the fact that they may be homosexual, but they may continue to deny that they have a gay or lesbian identity; (c) identity tolerance in which individuals become increasingly tolerant of the idea 
of a gay or lesbian identity but do not totally accept this identity; (d) identity acceptance in which individuals become progressively more accepting of a gay or lesbian identity; (e) identity pride in which individuals experience feelings of pride in a gay or lesbian identity and increasingly disclose this identity to others; and (f) identity synthesis in which individuals integrate their gay or lesbian identity into all other areas of their lives, and this identity becomes only one aspect of their total identity. Each of Cass's stages is discussed in more depth and paralleled with the stages in Ivey's $(1990,1993)$ DCT model later in this article.

\section{Gender Differences in Identity Development}

Since Cass (1979) first published her HIF model, some theorists have developed lesbian identity development models and noted that identity development may differ for lesbians (e.g., McCarn \& Fassinger, 1996; Sophie, 1986). Cass (1990) recognized that identity development can vary based on gender and listed several differences between the identity development of gay men and lesbians. First, men are more likely to have a sexually stimulating experience trigger the identity development process, whereas women are more likely to have an emotional experience trigger the process. Second, women are more likely to reject female gender roles, and men are more likely to modify male gender roles. Cass (1990) hypothesized that society views the male gender role as including power, knowledge, and independence, but society views the female gender role as passive and consisting of caring for others. Consequently, there may be less incentive for men to reject their male gender role. Finally, Cass believed that compared with gay men, lesbians often develop a lesbian identity later in life.

\section{Empirical Research}

To validate the HIF, Cass (1984) conducted a study in which 178 men and women were asked to complete the 210-item Homosexual Identity Questionnaire (based on the HIF model) and also asked to identify which stage of the HIF best described their current status along affective, behavioral, and cognitive dimensions. The results demonstrated that characteristics of the gay and lesbian identity development process could be categorized according to the HIF.

\section{IVEY'S DEVELOPMENTAL COUNSELING THERAPY MODEL.}

Ivey (1990) proposed a cognitive-behavioral counseling model that draws from Platonic philosophy and Piagetian cognitive development theory in emphasizing assimilation and accommodation, the dialectic, and consideration of Piagetian developmental stages in the systematic selection of therapeutic interventions. 
Piaget's $(1965,1973)$ stage model includes the sensorimotor, preoperation (termed late sensorimotor in the DCT), concrete operations, and formal operations stages. Piaget postulated that children move through these stages until they are between 11 and 15 years of age when they possibly reach the formal operations stage. According to Piaget, people derive meaning from information they receive from their environment by assimilating or accommodating the information. Assimilation is a Piagetian term used to describe the cognitive process whereby people incorporate information from the environment into existing schemata. In discussing Piaget's concepts, Ivey (1990), described assimilation as "the cognitive process by which we integrate new data into our lives. ... In assimilation, the individual acts on and imposes his or her perspectives on the environment" (p. 42). Accommodation is a Piagetian term used to describe the cognitive process whereby people develop new schemata to understand information from the environment. Ivey (1993) explained that accommodation is "the [cognitive] process through which we absorb and incorporate new information from the environment" (p. 89). "In accommodation, the individual receives (and possibly transforms) a stimulus from the environment" (Ivey, 1990, p. 42).

Ivey $(1990,1993)$ advanced Piaget's model to another level by theorizing that development is an ongoing process that is both circular and spherical. According to Ivey, individuals continue to develop cognitively after their childhood as they confront various issues in their lives such as sexual orientation identity.

Ivey's $(1990,1993)$ DCT model is composed of four cognitive levels with two subdivisions in each level. Unlike Piaget, Ivey did not believe that one level is superior to another. He viewed each developmental level as representing an alternative and valuable perspective. Like Piaget, Ivey recognized that many people will not reach higher levels of cognition.

\section{Sensorimotor Level}

The first level of the DCT is the sensorimotor level (Ivey, 1990, 1993). Individuals operating from an early sensorimotor subdivision level focus on their senses in making meaning of their current experiences. One example of this level occurs when people experience a traumatic event such as the death of a loved one. They may first focus on the pain and sadness of the event before being able to describe the event concretely. Ivey (1993) stated that sensorimotor experiences can also be positive, such as focusing on your senses on a beautiful day.

Ivey referred to Piaget's preoperational thinking stage as "late sensorimotor" level and stated that it is characterized by irrational or magical thoughts such as "shoulds" or "oughts." According to Ivey (1993), most individuals enter counseling with problems they are viewing from a preoperational perspective and not from a concrete perspective. An initial capacity for 
concrete thinking does not occur until the end of this stage as individuals begin to make the transition to concrete motor thinking.

\section{Concrete-Operational Level}

Individuals are operating from a concrete-operational level when they describe their experiences in concrete, detailed language (Ivey, 1990, 1993). They can describe their emotions but not reflect on them abstractly. For example, in response to her counselor's inquiry about how her week had been, a client stated, "I have a paper due next week, but I haven't started working on it. There's so much work to do, and I never seem to have the time. I guess I've been feeling more anxious than last week." This client is describing the details of her feelings and her assignments but is not thinking about why she is nervous. Although the capacity to think abstractly is not yet present, individuals at a late concrete operational level can use "causal, if/then thinking" (Ivey, 1993, p. 32). An example of a late concrete-operational statement is "I feel anxious because I have a paper due."

\section{Formal-Operational Level}

The formal-operational level is characterized by abstract thinking concerning emotions and experiences. Individuals in an early formal-operational level reflect on their concrete descriptions of events and recognize patterns. For example, "every time I have a paper due I put it off" and "every time I have a paper due I become anxious." Individuals in a late formal-operational level recognize "patterns of patterns" (Ivey, 1990, p. 296). They are able to comprehend that patterns of thoughts, behaviors, and emotions can be intertwined. For example, "I seem to have a pattern of putting my papers off and that seems to be related to the high level of anxiety I experience when I think about all of the work it takes to complete a paper."

\section{Dialectic or Systemic Level}

Ivey (1990) further theorized that adults are capable of abstract reasoning that extends beyond the formal-operations stage. He used the Platonic concepts of knowledge and intelligence to describe post-abstract thinking levels.

The dialectics or post-formal operations stage follows the formal-operations stage. According to Ivey (1990), dialectic or "dialogue . . centrally involves a discussion or search for truth or goodness" or an "examination of premises and assumptions" (p. 16). Adults in the dialectics stage reach new levels of comprehension by understanding that their view of the world (i.e., their knowledge) is influenced by their dialectic with the environment; in other words, they understand that they do not live in a vacuum and that they cannot avoid being influenced by the environment in which they exist. For example, the client, anxious about her paper, realized through discussions with her counselor that her anxiety could be traced to her belief as a child that she had to be 
perfect to receive positive reinforcement from her parents. She understood the dialectic between her family and herself and how it still continued to affect her.

Adults in the dialectics level understand that the knowledge they acquire is in constant flux. Individuals who reach a late dialectics stage experience what Ivey (1990) terms dialectic deconstruction of development when previously held knowledge or beliefs are deconstructed. In other words, dialectic deconstruction occurs when individuals experience a cognitive shift in their ways of making meaning of their environment. This deconstruction leads to new points of view. Fresh knowledge and viewpoints often lead to the beginning of another cycle through development, because this new knowledge is initially processed at less complex cognitive levels. Thus, for those individuals who are capable of thinking at post-formal operations levels, higher levels of thinking lead to new insight. This newfound insight is frequently reprocessed at sensorimotor and concrete operational levels before individuals process it at a more abstract level.

The client, just discussed, realized that her childhood belief that she had to be perfect continued to influence her today. As she contemplated the effect of this belief on her behaviors, she realized that her perfectionism made projects such as the paper seem more complicated than they really were. The image in her mind of the work it would take to finish the paper continued to build until she felt overwhelmed. When she felt overwhelmed, she experienced anxiety and resisted working on the paper to avoid thinking about it. The counselor processed this realization with her by first focusing on her feelings and cognitions at a sensorimotor level; then brainstorming ways to overcome the anxiety from a concrete operations level (e.g., dividing the project into smaller tasks and keeping a journal about the perfectionist thoughts that cycled through her mind when she felt overwhelmed).

\section{Developmental Counseling Therapy and the Counseling Process}

Ivey (1990) stated that most clients enter counseling viewing their presenting problem from a preoperational standpoint. Counselors may help clients focus on their presenting problem either at a sensorimotor level to ground the client in sensory reality or at a concrete operations level by examining specifics surrounding the presenting problem, before having them focus on more abstract levels of thinking (Ivey, 1990). On the other hand, some clients come to counseling at a formal-operations level and may have a tendency to over-intellectualize problems. Helping these clients first focus on their problems at a sensorimotor level will facilitate a more grounded awareness of issues.

Accordingly, the goal of a DCT counselor is to evaluate the cognitivedevelopmental level of clients regarding specific issues, and then use ap- 
propriate interventions based on this evaluation. Existing counseling theories and approaches are considered appropriate for each developmental level. For example, at the sensorimotor stage, counseling approaches such as $\mathrm{Ge}$ stalt counseling are helpful because these approaches help clients focus on their behavior and their senses. By evaluating clients' cognitive-developmental level and selecting appropriate counseling approaches, counselors can help clients learn more effective ways to deal with presenting problems. Consequently, Ivey's model of DCT

has highly specific implications for therapeutic practice. First, it is possible to identify the cognitive-developmental level of the client. Second, we can match our verbal and nonverbal interventions to the specific cognitive level of the client, thus facilitating exploration and later cognitive-developmental processes. In effect, it is feasible to match counseling skills and theory to the observable developmental level of the client. (Ivey, 1990, p. xiv)

Empirical support exists for the DCT model. Rigazio-DiGilio (1989) administered the Standard Cognitive-Developmental Interview (based on Ivey's model) and the Beck Depression Inventory to 20 clients identified as having depression to determine if clients' cognitive-developmental level could be evaluated based on the DCT model. The results demonstrated strong reliability and predictive validity for the DCT model. In addition, Heesacker, Rigazio-DiGilio, Prichard, \& Ivey (as cited in Rigazio-DiGilio, Ivey, \& Locke, 1997) demonstrated the reliability of the DCT model levels in a factor-analytic study of about 1,700 college students. Additional research is needed on the DCT model with a variety of populations, including gay men and lesbians.

\section{GAY AND LESBIAN AFFIRMATIVE DEVELOPMENT MODEL}

We propose a Gay and Lesbian Affirmative Development (GLAD) model to facilitate affirmative identity development with gay and lesbian clients by integrating the HIF and DCT models. Because each of the stages of Cass's (1979) HIF model has parallel stages with Ivey's (1990) model, there is merit in integrating these models. By referring to both models, counselors can use counseling approaches most appropriate for the cognitive-developmental level of the client.

Table 1 lists stages of Cass's model and the parallel stages of Ivey's model. Based on Ivey's suggestions for appropriate counseling approaches at each cognitive-developmental level, the third column of Table 1 lists possible counseling approaches appropriate for the developmental level of the client. The counseling approaches listed are suggestions only. Other counsel- 


\section{TABLE 1}

\section{Counseling Approaches Matched With Gay or Lesbian Identity and Cognitive-Developmental Levels}

\begin{tabular}{|c|c|c|}
\hline Cass (1979) & Ivey (1990) & Counseling Approach \\
\hline $\begin{array}{l}\text { Pre-identity confusion } \\
\text { Identity confusion }\end{array}$ & Sensorimotor & $\begin{array}{l}\text { Gestalt therapy } \\
\text { Relaxation techniques } \\
\text { Behavioral techniques }\end{array}$ \\
\hline $\begin{array}{l}\text { Identity comparison } \\
\text { Identity tolerance }\end{array}$ & Concrete operations & $\begin{array}{l}\text { Reality therapy } \\
\text { Rational emotive therapy } \\
\text { Behavioral techniques }\end{array}$ \\
\hline $\begin{array}{l}\text { Identity acceptance } \\
\text { Identity pride }\end{array}$ & Formal operations & $\begin{array}{l}\text { Person-centered therapy } \\
\text { Reframing techniques } \\
\text { Psychodynamic therapies } \\
\text { Existential therapy }\end{array}$ \\
\hline Identity synthesis dialectic & Deconstruction & $\begin{array}{l}\text { Feminist therapy } \\
\text { Family therapy } \\
\text { Dialectic awareness } \\
\text { techniques }\end{array}$ \\
\hline
\end{tabular}

ing approaches may also be appropriate, and some counseling approaches may be appropriate at more than one level. The key is to assess clients' sexual orientation identity and cognitive-developmental levels based on the descriptions of the levels in the following sections and to systematically apply appropriate counseling approaches based on this assessment.

The GLAD model is based on the parallels and counseling approaches outlined in Table 1 and presented as follows. After descriptions of each of the four broad cognitive levels are given, possible interventions are discussed. These interventions and approaches are suggestions based on our experiences working with gay and lesbian clients. The interventions offered are suggestions only, and other interventions may also be identified that complement counselors' integrative styles and match clients' developmental levels. In addition, GLAD model interventions should be used within a gay or lesbian affirmative counseling approach (i.e., an approach that is client centered and gay and lesbian affirmative). Finally, the GLAD model may be used to identify specific interventions during a single counseling session when gay or lesbian identity issues surface or as a means to integrate developmentally appropriate interventions into an overall counseling process lasting many sessions with gay or lesbian clients who have identity issues. 


\section{PARALLEL STAGES}

\section{Sensorimotor}

Pre-identity confusion/early sensorimotor. Ivey (1993) described a Piagetian sensorimotor child as being "unable to separate the self from others" and having "little sense of self" (p. 30). Adults in Stage 1 focus solely on their senses in relation to their sexual orientation; however, they have little sense of their self in relation to their sexual orientation. In essence, they do not connect these initial feelings with a gay or lesbian self, and they cannot separate from the feelings and beliefs that they are heterosexual. Individuals may have a vague realization of a physical sensation, an emotion, or a behavior that is different from those of other individuals in their environment, but they only sense these differences. Gay and lesbian clients in later stages of development often state that they somehow knew they were different at earlier stages of their life but could not define their feelings. A preidentity confusion/early sensorimotor stage could last for years or could be an early sensory (but not conscious) recognition that something about them is different from others in their environment (Cass, 1990; Ivey, 1990).

Identity confusion/late sensorimotor. In Stage 2, identity confusion, individuals focus on behavior, affect, and cognitions in realizing that they might be homosexual. Because they are beginning to define their behaviors, affects, or cognitions, individuals have an initial amount of concrete thinking. This initial, conscious realization causes confusion because previously they had assumed that their feelings and behaviors were heterosexual. This assumption may have been strengthened by people in individuals' environments who either directly or indirectly assumed that everyone was heterosexual. This stage may be marked by low self-esteem and negative feelings about being gay or lesbian. Individuals in this stage may use irrational thinking to deny that they are gay or lesbian (i.e., "It's just a phase I'm going through. I'm just admiring same-sex individuals who have the type of body I would like to have."). They are not able to think concretely enough to define these thoughts and emotions (Cass, 1990; Ivey, 1990).

Sensorimotor counseling approaches and interventions. Ivey (1990) stated that most clients will come to counseling handling presenting issues at a preoperational or late sensorimotor level and that it is helpful to refocus clients at an early sensorimotor level before confronting late sensorimotor irrational thoughts. In addition, Ivey suggested helping clients focus on their senses even when they present issues from a more concrete or abstract level to help them connect their cognitions with their senses.

Counselors, then, can initially assist clients to focus on their senses (sensorimotor thinking). A powerful intervention is to lead gay and lesbian clients through a guided imagery exercise, asking them to focus on a time in their lives when they remember having a vague feeling that there was 
something missing or that they were different from others around them. Counselors can ask the clients to describe the situation in detail (including what they saw, heard, felt, and sensed) to help them "connect" from a sensorimotor level with their first feelings of being different. Counselors can help the clients progress to a late sensorimotor stage by asking them to focus on their initial thoughts about their feelings of being different. For example, what was going through their minds at this time? How did they define their feelings? Did they rationalize meanings for their feelings?

\section{Concrete Operations}

Identity comparison/early concrete operational. Whereas in Stage 2 individuals are confused about and unable to define their same-sex feelings and thoughts, in Stage 3 individuals are able to acknowledge that the feelings and thoughts could be homosexual. In this stage, individuals are able to concretely express feelings of same-sex attraction but only to acknowledge that they may be gay or lesbian. The difference between homosexual and gay or lesbian is an important distinction for understanding clients at this stage. Clients may have an initial recognition that behaviors, thoughts, or feelings are homosexual (i.e., same sex); however, this recognition does not mean that they connect a gay or lesbian identity with their selves. In essence, clients in this stage are separating their selves from their homosexual thoughts, feelings, or behaviors. Connecting a gay or lesbian identity with the self would require abstract thinking beyond a labeling of feelings, behaviors, and cognitions (Cass, 1990; Ivey, 1990).

Identity tolerancellate concrete operational. Individuals in Stage 4 are able to use causal, if-then logic to reason that "if I have same-sex feelings, thoughts, or behaviors, then I am probably gay or lesbian." They experience the realization that the behaviors, feelings, and cognitions labeled as homosexual probably can be connected to a gay or lesbian self. Individuals tolerate this new understanding of themselves, acknowledging the possibility of a gay or lesbian self but not necessarily viewing it in a positive manner. Individuals may view their homosexual feelings as bad or they may acknowledge that their behavior is homosexual but still not make a total commitment to a gay or lesbian identity, which still requires abstract thinking (Cass, 1990; Ivey, 1990). Individuals may feel torn between an increasing awareness of their homosexuality and the lingering past belief that they were heterosexual. They may continue to label their homosexual feelings, thoughts, and cognitions as bad. Ivey stated that "the complexity and reality of mixed or ambivalent feelings is absent. . . . Feelings are often simplified as 'good' or 'bad'" (Ivey, 1990, p. 94).

Concrete operations counseling approaches. Clients in concrete operational stages are not thinking abstractly about their homosexuality and may not yet understand that homosexual feelings, behaviors, and cognitions are re- 
lated to a gay or lesbian identity. Counselors can help clients focus on specific examples of their thoughts and behaviors and help them recognize irrationalities through the use of counseling approaches such as cognitive behavioral therapies and reality therapy (Ivey, 1990).

One gay male client remarked, "I know that I'm probably gay, but I still wonder if I can change it. It's not right. It's wrong to be gay. I wish that I could change my sexuality." Using reality therapy, counselors can help clients process the reality of their sexuality and what they can and cannot control. For example, the counselor responded, "I understand that you are not happy about the possibility that you are gay, but it is doubtful that you can change your sexuality. It's not something that you can control. In fact, you do not have to make a decision on whether you are gay or not. I wonder, though, if you can think of things in your life that you can control." At this point the client was encouraged to brainstorm about things he could do such as reading books about being gay, joining a coming-out group, or keeping a journal about his feelings.

A lesbian client stated, "I know that I will always be lonely and will never be accepted by my family. This cannot be happening to me." Using a cognitive behavioral approach, counselors can point out that clients cannot predict the future. It is possible that they will be lonely and not be accepted, but it is also possible that they will develop a supportive network of friends and be accepted. Clients can be helped to recognize that negative messages they received about being gay or lesbian from their environment have been internalized and frequently lead to irrational thoughts. When clients express feelings of depression or anxiety at this stage, they can be encouraged to process these feelings from a sensorimotor level, then encouraged to discuss the thoughts that are going through their mind, and finally helped to think of what they can do.

\section{Formal Operations}

Identity acceptancelearly formal-operational. In Stage 5, individuals are able to make a commitment to themselves that they are gay or lesbian. In other words, they connect rather than separate their homosexual feelings, thoughts, and behaviors to a gay or lesbian self. They are able to recognize patterns such as "when I fall in love or when I am attracted to someone they are of the same sex." Individuals in Stage 5 are using abstract logic to reason that "I have homosexual feelings and behaviors; therefore, I am gay or lesbian." As they reflect on their identity, they become progressively more accepting of their same-sex feelings and the idea of being gay or lesbian (Cass, 1990; Ivey, 1990).

Identity pridellate formal-operational. Individuals in Stage 6 begin to contemplate the patterns in their lives and realize how their experiences, thoughts, and feelings in the past have been connected to their gay or lesbian identity. At this stage there may be extreme anger as they realize 
that many of their past patterns (i.e., hiding or denying their gay or lesbian identity) have been due to societal homophobia they have internalized and fears of being rejected. In addition, individuals frequently experience a feeling of pride in being gay or lesbian and increasingly come out to others. An individual's desire to come out corresponds with a desire to discuss and compare his or her coming-out experiences with other gay men and lesbians (Cass, 1990; Ivey, 1990).

Formal operations counseling approaches. Clients in formal operations stages have accepted their gay or lesbian identity but have not integrated this identity into other aspects of their lives. Like young adults becoming acquainted with the idea that they are no longer children, gay and lesbians become acquainted with the idea that they are gay or lesbian. Counselors can help clients become comfortable with and better understand their identities by demonstrating "unconditional regard" for clients as they become acquainted with their newly accepted identity, by helping clients get in touch with their feelings, and by continuing to help clients understand that their homosexual feelings, behaviors, and cognitions are related to their gay or lesbian identity. Counselors can help clients see patterns related to their sexual orientation by asking "when have you felt this way before?" When clients recall feelings from the past, counselors can help them process these feelings at a sensorimotor level before helping them see the patterns of their feelings. For example, clients may recall past feelings of differentness that they are now able to connect to a pattern of feeling different as they became aware that they are gay or lesbian. Person-centered therapy, psychodynamic therapies, and reframing techniques (Ivey, 1990) can help clients process these patterns at a formal operations level.

One lesbian client stated that "I know I am gay, but I just cannot be happy about it like other people." The counselor can respond by acknowledging the clients' feelings (e.g., "You understand that you are gay, but you are not happy about it because it is not who you expected to be."). Psychodynamic therapies such as object relations can be used to help the clients recognize that one part of the self accepts being gay or lesbian and another "judgmental self" believes that it is bad. Demonstrating empathy is also important when clients reach a pride level and experience anger toward negative societal messages and the realization that in the past they had presented a false self (i.e., heterosexual self) to others to hide their true self (i.e., gay or lesbian self), because they were afraid of being rejected.

As clients reach late formal operations/identity pride, they can be challenged with reframing techniques when they make all-encompassing statements such as "straight people are all anti-gay." Counselors can facilitate a cognitive shift by pointing out examples of supportive people who are not gay or lesbian, such as parents involved in Parents and Friends of Lesbians and gay men (PFLAG). 


\section{Dialectics}

Identity synthesis/early dialectic. In Stage 7, individuals are able to integrate their gay or lesbian identity into other aspects of their lives (e.g., gender identity, cultural identity, religious identity). They are able to view themselves as having a variety of identities that are intertwined. Individuals have less anger, because they are able to look at other people's reactions to their sexuality in the context of the situation. For example, individuals at this level may be able to reflect on the way their parents reacted to their coming out and realize that parents go through a developmental process of acceptance similar to their own. Individuals may deal with existential issues such as the following: How does my gay identity fit into the context of society? How does my being gay affect the way I interact with other people? What does it mean for me to be gay? (Cass, 1990; Ivey, 1990).

Late dialectic/systemic and deconstruction. The final stage, Stage 8, is the end of one cycle of cognitive awareness and the beginning of another cycle. Cass (1990) did not identify a stage beyond identity synthesis; however, a late dialectic stage could be viewed as a late identity synthesis stage. Individuals are able to "think about thinking about thinking" (Ivey, 1990, p. 16). In this stage, individuals gain new insight into being gay or lesbian by realizing that their understanding of their sexual orientation and how it relates to their total identity is in constant flux. They realize that at various times in their lives they have an understanding of their inner-self that brings new insight and new knowledge. New insight is processed from a sensorimotor level, thus leading to a spiral-like process of development. For example, individuals at this stage of development may be confronted with a situation that triggers a realization that there are parts of the self that still harbor internalized homophobia. As they process this information, they may recycle through another developmental cycle as new insights are initially processed at a sensorimotor level.

It is difficult to determine how many individuals reach this high level of abstract thinking. Nevertheless, according to Ivey (1990), individuals who do reach this level of cognition will experience another development cycle as they initially process new insights at more concrete levels.

Dialectical counseling approaches. Counselors can use deconstruction theory, modern feminist therapy, and other philosophical approaches to help clients in dialectic stages as they attempt to examine the meaning of their existence. In the formal operations stage, some gay or lesbian clients may accept the reality that they are gay or lesbian but still feel that they are inferior to heterosexuals. Other clients may feel that they are superior to heterosexuals, because they believe that all heterosexuals are close-minded. In a dialectic stage, clients recognize the effect their environment has had in shaping their views. Counselors can help clients understand various dialectics in their lives such as (a) the dialectics between both their families and themselves and other aspects of their environments (e.g., societal views, 
friends, coworkers) and themselves; (b) the internal dialectic between the part of themselves comprising negative, internalized messages from society and the gay or lesbian part of the self; and (c) the dialectic comprising transferences that occur when they project their own internalized homophobia onto others. Counselors can use an approach similar to feminist therapy to point out how clients' feelings of inferiority that are related to their internalized homophobia have been shaped by a heterosexist environment in which people assume that everyone is heterosexual or should be.

One older gay man who had been openly gay for over 25 years remarked that he was among a group of people when someone told an antigay joke. $\mathrm{He}$ did not say anything in response to the joke and realized later that he had felt he did not have a right to protest the joke. In that moment, he felt inferior to the others in the group. In contemplating the incident he realized that he still had internalized homophobia, and he realized that it would most likely be a lifelong struggle to fully accept his self. He further realized that he had projected his unaccepting self onto the people in the group, because he really did not know what the other people in the group felt about the joke or about gay men or lesbians in general.

\section{Identity Foreclosure and Horizontal Development}

Cass (1990) acknowledged that it is possible for identity foreclosure to occur during the developmental process. Identity foreclosure occurs when clients become stagnated at an early stage without reaching later stages. Using Ivey's (1990) approach, counselors can help clients move beyond periods of foreclosure.

Ivey (1990) recognized that individuals may develop horizontally before progressing vertically to other stages. Consequently, clients can have development within development because "the building of an adequate foundation is usually required before moving to another stage" (Ivey, 1990, p. 8). Thus, it is important that counselors accept clients at their current levels of both vertical and horizontal development and encourage further client development through matching (or intentionally mismatching) the intervention to the developmental level of the client. However, counselors should not assume that all clients want to move forward based on counselors' timetables. Some gay and lesbian clients may choose to remain at various stages of development due to unmitigated circumstances.

\section{Spherical Development}

Cass (1990) outlined a linear model of identity development. Other theorists (Coleman, 1981/1982; Troiden, 1984, 1988) have developed gay and lesbian identity models similar to Cass's model; however, these models differ in their views of the developmental process. Coleman believed that 
individuals can move both forward and backward as they develop. Similarly, Troiden $(1984,1988)$ viewed the development of an identity as being a spiraling process whereby persons can both progress and regress as they form an identity.

Ivey (1990) wrote that development is simultaneously linear, cyclical, and spiraling within a spherical framework. Individuals may move through developmental stages over long periods of time or in a matter of seconds. For example, an individual at a formal operations stage of functioning could be confronted with an issue and move to a sensorimotor or preoperational level while initially contemplating the issue. In a matter of seconds, the individual could move through a cognitive process in which he or she thought about the issue from a sensorimotor mindset to a pre-operational mindset to a concrete-motor mindset and back to a formal-operations mindset. This process may be more accurately described as integration rather than regression.

Central to the developmental therapy model is the belief that developmental progressions recycle to the beginning, back to where we started; but our awareness of this progression and our return to the starting point is paradoxically a continuing new awareness. (Ivey, 1990, p. 3)

Therefore, it is important for counselors of gay and lesbian clients to be mindful that clients may process issues regarding their sexual orientation identity from varying cognitive-developmental levels. The following case study demonstrates how a counselor can assess a client's sexual orientation identity/cognitive developmental level and systematically apply appropriate counseling approaches based on this assessment. Using an integrative model does not mean haphazardly trying various techniques; it implies integrating into counselors' own styles techniques from various theoretical schools in a systematic and appropriate manner.

\section{Case Study}

$\mathrm{Cal}$ (not his real name), a 29-year-old man, entered counseling in a highly agitated and anxious state over the breakup of a friendship. Cal had developed a close nonsexual friendship with Stan (not his real name), who apparently was heterosexual. Stan's marriage after a short-term relationship with a woman precipitated Cal's anxiety and request for counseling services. Initially, Cal's thought processes were disjointed and irrational, stemming from a high level of emotionality. He believed that he could not live without Stan, but at the same time could not accept his strong feelings for Stan. After assessing suicidal ideation and establishing a no-suicide con- 
tract, Cal's counselor began the process by engaging $\mathrm{Cal}$ in some relaxation activities in an effort to help Cal relax and focus on the specific details of the situation. The counselor used Gestalt techniques to help Cal begin to deal with his unfinished business of verbalizing his feelings of anger and hurt to Stan. The counselor also used Gestalt techniques to help Cal carry on a dialogue with the part of himself that did not accept his feelings for Stan and the part that acknowledged his feelings for Stan.

As the anxiety became more manageable, the counselor began focusing on the specific parameters of the relationship, primarily using reality therapy and rational emotive therapy techniques to help Cal examine the irrational thought processes both during the relationship and after Stan had married. For example, Cal believed that he should not have feelings for Stan and rationalized these feelings in denying that he was gay. It was during this phase of the counseling process that Cal began to examine his own ambiguity about his sexual orientation identity. It became apparent that $\mathrm{Cal}$ knew he was gay but was conflicted in this knowledge by strong parental and religious messages he had received. At this point in the process, Cal's counselor began using a less directive approach, integrating more personcentered principles and reframing client statements to help Cal become more self-accepting. As Cal gradually became more accepting of his sexual orientation, he sought out other gay men through a local gay and lesbian community center and joined a "coming-out group" for gay men. During the second year of counseling, Cal became increasingly more accepting of himself and began to show signs of identity pride. He came out to his family and his coworkers, and he related to the counselor that he enjoyed buying gay literature and watching the expression of the salesclerk. Cal attended gay pride festivities that summer and continued to make new friends. When $\mathrm{Cal}$ was operating at a formal operations/identity pride level, the counselor used a more nondirective, psychodynamic approach to help $\mathrm{Cal}$ explore other areas related to and separate from his sexual orientation. During this time, Cal would frequently revisit some aspect of his development that would result in a great deal of emotion, often followed by early concrete-operations thinking. During these times, the counselor would encourage $\mathrm{Cal}$ to use the relaxation techniques learned early in the counseling process and again use reality therapy and rational emotive therapy techniques to work with the irrational thought processes as the developmental process was recycled.

\section{CONCLUSION}

The purpose of this article was to provide a broad overview of the GLAD model. The ideas presented are an initial attempt to offer a means to pro- 
vide gay and lesbian clients with a gay or lesbian affirming counseling approach. Research is needed both to test the proposed counseling approach and to determine the degree to which various counseling approaches are successful in helping clients more effectively develop a positive identity. Finally, gay and lesbian counseling approaches similar to those used in feminist counseling are needed to address the dialectic between gay men or lesbians and society and the impact this dialectic has on gay or lesbian clients. Using a parallelism between Cass's Homosexual Identity Formation Model and Ivey's Developmental Counseling Therapy Model, counselors can begin to formulate counseling models that outline effective counseling approaches for helping gay and lesbian clients develop a positive sexual orientation identity.

\section{REFERENCES}

Atkinson, D. R., Morten, G., \& Sue., D. W. (1993). Counseling American minorities: A cross-cultural perspective. Madison, WI: Brown \& Benchmark.

Beard, J., \& Glickauf-Hughes, C. (1994). Gay identity and sense of self: Rethinking male homosexuality. Journal of Gay and Lesbian Psychotherapy, 2(2), 21-37.

Brady, S., \& Busse, W. J. (1994). The Gay Identity Questionnaire: A brief measure of homosexual identity formation. Journal of Homosexuality, 26(4), 1-22.

Cass, V. C. (1979). Homosexual identity formation: A theoretical model. Journal of Homosexuality, 4, 219-235.

Cass, V. C. (1984). Homosexual identity formation: Testing a theoretical model. The Journal of Sex Research, 20, 143-167.

Cass, V. C. (1990). The implications of homosexual identity formation for the Kinsey model and scale of sexual preference. In D. P. McWhirter, S. A. Sanders, \& J. M. Reinisch (Eds.), Homosexuality/heterosexuality: Concepts of sexual orientation (pp. 239-266). New York: Oxford University. Chickering, A. W., \& Reisser, L. (1993). Education and identity San Francisco: Jossey-Bass.

Coleman, E. (1981/1982). Developmental stages of the coming out process. Journal of Homosexuality, 7, 31-43.

Erikson, E. H. (1968). Identity: Youth and crisis. New York: Norton.

Fassinger, R. E. (1991). The hidden minority: Issues and challenges in working with lesbian women and gay men. The Counseling Psychologist, 19, 157-176.

Hall, A. S., \& Fradkin, H. R. (1992). Affirming gay men's mental health: Counseling with a new attitude. Journal of Mental Health Counseling, 14, 362-374.

Hancock, K. A. (1995). Psychotherapy with lesbians and gay men. In A. R. D'Augelli \& C. J. Patterson (Eds.), Lesbian, gay and bisexual identities over the lifespan: Psychological perspectives (pp. 398 -432). New York: Oxford University. 
Ivey, A. E. (1990). Developmental therapy. San Francisco: Jossey-Bass.

Ivey, A. E. (1993). Developmental strategies for helpers: Individual, family, and network interventions. North Amherst, MA: Microtraining Associates.

Kuehlwein, K. T. (1992). Working with gay men. In A. Freeman \& F. M. Dattilio (Eds.), Comprehensive casebook of cognitive therapy (pp. 1-19). New York: Plenum.

Levine, H., \& Evans, N. (1991). The development of gay, lesbian, and bisexual identities. In N. Evans \& V. Wall (Eds.), Beyond Tolerance: Gays, lesbians, and bisexuals on campus. Washington, DC: American College Personnel Association.

Malyon, A. K. (1993). Psychotherapeutic implications of internalized homophobia in gay men. In C. Cornett (Ed.), Affirmative dynamic psychotherapy with gay men (pp. 77-92). Northvale, NJ: Aronson.

McCarn, S. R., \& Fassinger, R. E. (1996). Re-visioning sexual minority identity formation: A new model of lesbian identity and its implications for counseling and research. The Counseling Psychologist, 24, 508-534.

McHenry, S., \& Johnson, J. W. (1993). Homophobia in the therapist and gay or lesbian client: Conscious and unconscious collusions in self-hate. Psychotherapy, 30, 141-151.

Miranda, J., \& Storms, M. (1989). Psychological adjustment of lesbians and gay men. Journal of Counseling \& Development, 68, 41-45.

Myers, J. (1992). Wellness, prevention, development: The cornerstone of the profession. Journal of Counseling \& Development, 71, 136-139.

Piaget, J. (1965). The moral judgement of the child. New York: The Free Press.

Piaget, J. (1973). The child and reality: Problems of genetic psychology. New York: Grossman.

Rigazio-DiGilio, S. A. (1989). Developmental theory and therapy: A preliminary investigation of reliability and predictive validity using an inpatient depressive population sample (Doctoral dissertation, University of Massachusetts, 1989). Dissertation Abstracts International, 50(5), 216-313.

Rigazio-DiGilio, S. A., Ivey, A. E., \& Locke, D. C. (1997). Continuing the post-modern dialogue: Enhancing and contextualizing multiple voices. Journal of Mental Health Counseling, 19, 233-255.

Shannon, J. W., \& Woods, W. J. (1991). Affirmative psychotherapy with gay men. The Counseling Psychologist, 19, 197-215.

Sophie, J. (1986). A critical examination of stage theories of lesbian identity development. Journal of Homosexuality, 12(2), 39-51.

Troiden, R. R. (1984). Self, self-concept, identity, and homosexual identity: Constructs in need of definition and differentiation. Journal of $\mathrm{Ho}$ mosexuality, 10(3/4), 97-109.

Troiden, R. R. (1988). Homosexual identity development. Journal of Adolescent Health Care, 9, 105-133. 